\title{
ROV Observations on Reproduction by Deep-Sea Cephalopods in the Central Pacific Ocean
}

\author{
Michael Vecchione* \\ NOAA/NMFS National Systematics Laboratory, National Museum of Natural History, Washington, DC, United States
}

Telepresence-enabled operations by remotely operated vehicles (ROVs) allow many researchers a unique perspective on morphology, behavior, and small-scale distributions of deep-sea animals. I present some examples of cephalopod natural history from recent ROV dives in the central Pacific Ocean. These examples include clues to reproductive behavior of deep-sea squids and cirrate "dumbo" octopods. During March 7-12, 2017, the ROV Deep Discoverer (D2) operating from NOAA Ship Okeanos Explorer recorded high-definition video of several squid in the genus Chiroteuthis. These included a mature

OPEN ACCESS

Edited by: Diva Amon, Natural History Museum, United Kingdom

Reviewed by: Rui Rosa,

University of Lisbon, Portugal José Marian,

University of São Paulo, Brazil Mark C. Benfield, Louisiana State University, United States

*Correspondence: Michael Vecchione vecchiom@si.edu

Specialty section: This article was submitted to Deep-Sea Environments and Ecology, a section of the journal Frontiers in Marine Science

Received: 01 April 2019 Accepted: 28 June 2019 Published: 16 July 2019

Citation:

Vecchione M (2019) ROV Observations on Reproduction by Deep-Sea Cephalopods in the Central Pacific Ocean. Front. Mar. Sci. 6:403.

doi: 10.3389/fmars.2019.00403 male, a mature female, and a moribund squid identifiable as $C$. picteti. The female had obviously mated, with spermatangia implanted in many locations, and was holding in its arms another squid that appeared to be another Chiroteuthis. Considered together, these observations may indicate a deep-sea spawning aggregation and, possibly, sexual cannibalism. Another series of observations by D2 revealed eggs of cirrate octopods attached to octocorals. The remarkable thing about these observations was that in two of them (March 18 and May 4) the egg chorion had swollen and burst the external egg capsule. This may explain how the hatching embryo is able to escape from the tough protective coating secreted by the oviducal gland of cirrates but not secreted by the better-known incirrate octopods.

Keywords: Cephalopoda, Cirrata, egg, Chiroteuthidae, mating, aggregation, cannibalism

\section{INTRODUCTION}

The Campaign to Address Pacific Monument Science, Technology, and Ocean Needs (CAPSTONE) was a multi-year study of deep-water United States marine protected areas (Kennedy et al., in press). Observations from the Remotely Operated Vehicle (ROV) Deep Discoverer in 2017 included several that were instructive about reproduction by deep-sea cephalopods. I present observations contributing to two separate topics relative to reproduction by deep-sea cephalopods: (1) Cirrate octopod eggs and how they likely hatch, and (2) Mating, possibly in a population aggregation, and possible sexual cannibalism in a chiroteuthid squid species.

Unlike more familiar incirrate octopods, cirrates coat their eggs in a thick layer secreted by the oviducal gland (Vecchione et al., 1998). Vecchione et al. (1998) found that this coating rapidly hardens when exposed to seawater. Also in contrast with incirrates, recent observations of a fully developed cirrate embryo (Shea et al., 2018) found no evidence of a hatching gland. How the hatchling escapes from the thick, hard coating over the chorion has therefore been a mystery. 
Observations on mating by deep-sea squids are few, but have indicated diverse patterns (Hoving et al., 2014). Although squids of the genus Chiroteuthis have been observed from ROVs and other submersibles several times, especially in the eastern North Pacific (Burford et al., 2015), in situ observations of mating behavior or mated individuals are, until now, unknown.

\section{MATERIALS AND METHODS}

The general rationale and Methods for CAPSTONE are summarized by Kennedy et al. (in press). Briefly, the CAPSTONE cruises featured "telepresence-enabled" dives by ROVs, in which

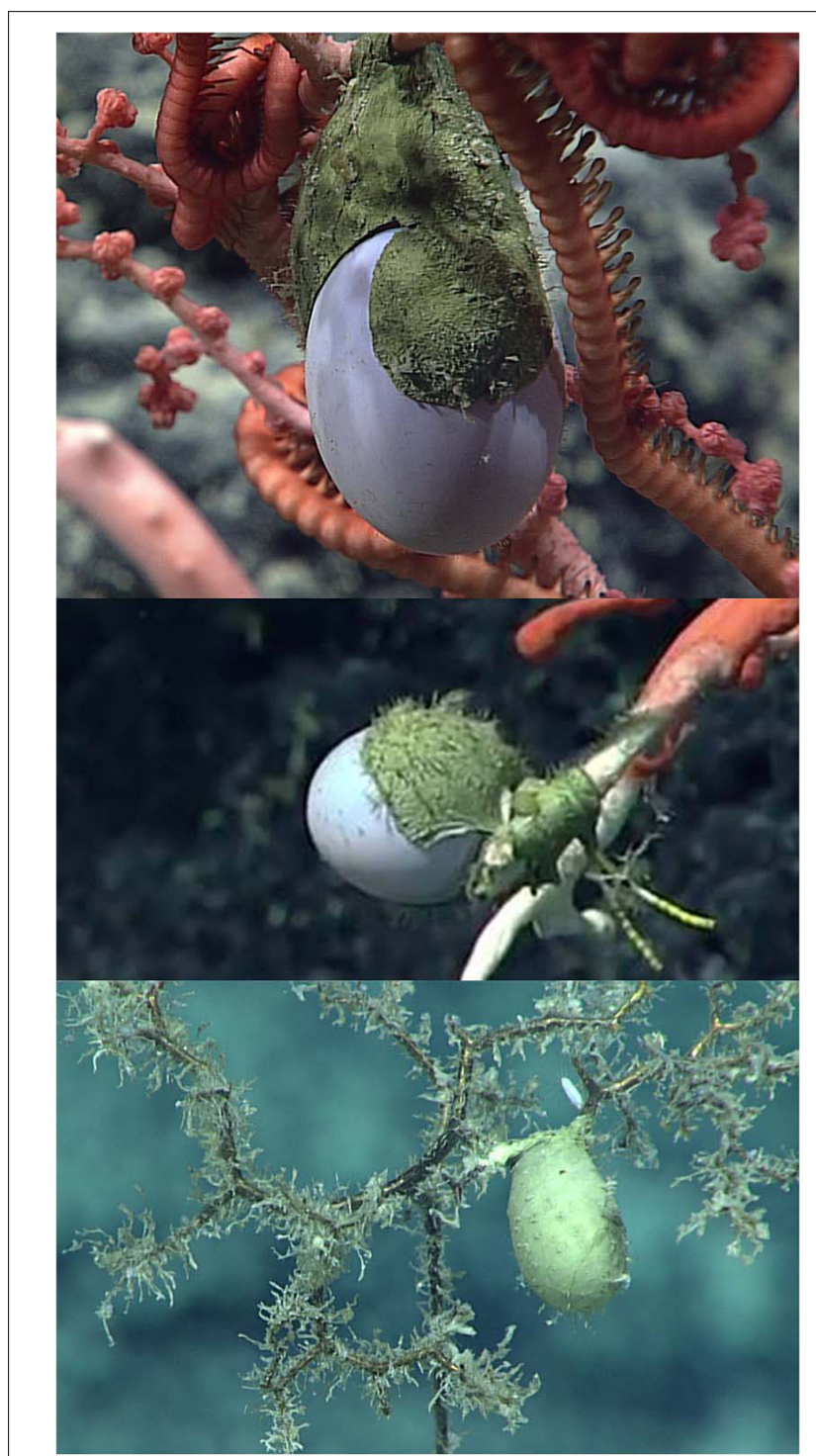

FIGURE 1 | High-definition video frames of cirrate octopod eggs. See Table 1 for associated environmental data. In top and middle images the outer coating has ruptured and the smooth chorion is visible. The bottom image is intact and differs from the top and middle in both morphology and the cnidarians species to which it is attached. the live video feed and associated data are transmitted ashore and distributed in "real time" via the internet so that scientists ashore could participate in ROV operations. The ROV operated from

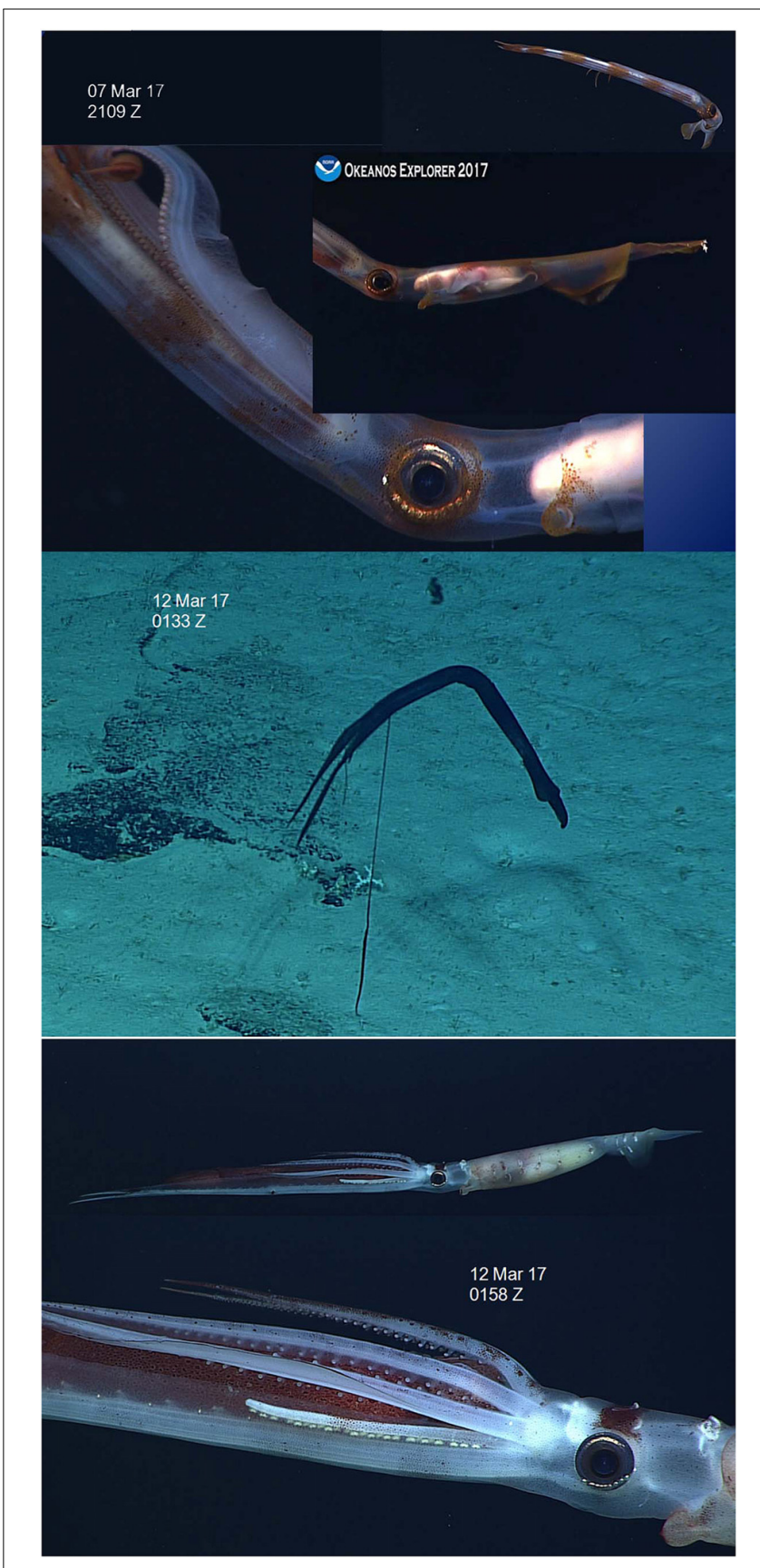

FIGURE 2 | High-definition video frames of squids in the genus Chiroteuthis. See Table 2 for associated environmental data. Top (with insets): a mature male with spermatophores stored in Needham's sac; Middle: modibund, or perhaps dead, individual with tentacle club visible; Bottom (with inset): a mature, mated female with spermatangia (implanted sperm masses) visible on the head, mantle, and fins. This female was holding a long, narrow squid (expanded chormatophores visible) in its arms; this engulfed squid, presumably another Chiroteuthis, was motionless and the chromatophores were not contracting. 
NOAA Ship Okeanos Explorer. Following each cruise, videos and data are archived ashore and available online for further examination and analyses.

During the CAPSTONE cruises, three ROV dives on three separate dates observed cirrate eggs on two different cruise legs (Table 1). Two other dives within a few days of each other on a single cruise leg (Table 2) included encounters with the squid genus Chiroteuthis (see Section "Discussion” for inference of specific identification), all of which included indications consistent with a mating event.

\section{RESULTS}

\section{Cirrate Eggs}

Three observations (Table 1 and Figure 1) by the ROV Deep Discoverer (D2) revealed eggs of cirrate octopods attached to cnidarian colonies. The remarkable thing about these observations was that in two of them (Figure 1, Top and Middle) the egg chorion had swollen and burst the external egg capsule. These two observations were very similar in overall morphology and both eggs were attached to "bubblegum" octocorals. The third observation (Figure 1, Bottom) differed in both appearance and attachment from the other two. The external egg capsule was not ruptured and it also differed slightly in surface texture from the other two capsules. It also appeared not quite as dark as the other two, although this could be an artifact of the lighting from the ROV. The substrate to which it was attached was a different octocoral not a "bubblegum".

\section{Chiroteuthis}

During March 7-12, 2017, D2 recorded high-definition video of several squid in the genus Chiroteuthis. These included a mature male with spermatophores in its Needham's sac (Figure 2, Top), a mature female with well-developed nidamental glands as well as large obvious ovary (Figure 2, Bottom), and a moribund squid (Figure 2, Middle). The female had obviously mated, with spermatangia implanted in many locations, and was holding in its arms another long, thin squid (identifiable as a squid from its chromatophores in the high-definition video) that appeared to be another Chiroteuthis. The eye photophores on the male and the female were in multiple series of discrete, circular organs (as opposed to photogenic strips), but whether there were two or three series per eyeball could not be determined for certain. The eye photophoress could not be seen on the moribund individual, but its tentacle club was visible.

\section{DISCUSSION}

We have known since the late 1800s that cirrate octopods attach their eggs to deep-sea octocorals. However, unlike incirrate octopods with their well-known maternal egg care, cirrates protect their eggs with a thick, tough coating. It has been unclear how cirrate hatchlings can get through that coating when they hatch. Indeed, Shea et al. (2018) looked for, but did not find, a hatching gland, similar to those used by incirrate octopods to escape the egg, in a cirrate embryo. Cephalopod eggs swell during embryonic development (Boletzky, 1989). These observations from the ROV Deep Discoverer show that swelling of the cirrate egg chorion bursts the end of the coating away from the attachment point. This would allow the cirrate embryo to hatch through the chorion as other cephalopods do. This may explain how the hatching embryo is able to escape from the tough protective coating secreted by the oviducal gland of cirrates but not secreted by the better-known incirrate octopods. However, the mechanism used by the cirrate embryo to penetrate the chorion remains a mystery. Identification of these observations is not possible based on our current state of knowledge about cirrate eggs.

Villanueva (1992) illustrated egg capsules of species in the cirrate genus Opisthoteuthis. His observations included a smooth distal area in the egg capsule of $O$. agassizii that appears to correspond with the ruptured area in the first two observations here. Also, Villanueva (1992) found a faint line on the egg capsule of $O$. voss $i$ that might correspond with the line of rupture on the present observations.

TABLE 1 | Observations on cirrate octopod eggs.

\begin{tabular}{|c|c|c|c|c|c|c|c|}
\hline Cruise & Date & Time (UTC) & Figure & Latitude & Longitude & Depth (m) & $\operatorname{Temp}^{\circ} \mathrm{C}$ \\
\hline EX1703 & 18 March 2017 & $211945 Z$ & 1 (top) & 0.80 & -176.7 & 2215 & 2.1 \\
\hline EX1705 & 05 May 2017 & $010036 Z$ & 1 (middle) & -1.51 & -159.5 & 1626 & 2.7 \\
\hline EX1705 & 10 May 2017 & $221527 Z$ & 1 (bottom) & 5.85 & -162.5 & 2117 & 2.2 \\
\hline
\end{tabular}

UTC: Universal time coordinated.

TABLE 2 | Observations on chiroteuthid squids.

\begin{tabular}{|c|c|c|c|c|c|c|c|}
\hline Cruise & Date & Time (UTC) & Figure & Latitude & Longitude & Depth (m) & Temp ${ }^{\circ} \mathbf{C}$ \\
\hline EX1703 & 07 March 2017 & $210944 Z$ & 2 (top, including insets) & -11.05 & -171.1 & 1105 & 4.1 \\
\hline EX1703 & 12 March 2017 & $013355 Z$ & 2 (middle) & -4.15 & -174.9 & 1035 & 4.3 \\
\hline EX1703 & 12 March 2017 & $015813 Z$ & 2 (bottom, incl. inset) & -4.15 & -174.9 & 1035 & 4.3 \\
\hline
\end{tabular}

UTC: Universal time coordinated. 
Specific identifications are often a problem when dealing with in situ imagery for which specimens have not been collected. This series of observations of squid belonging to the genus Chiroteuthis, when considered together, indicate reproductive behavior unknown in cephalopods. The series of discrete eye photophores are consistent with species of both the C. picteti species group and the C. joubini group (Roper et al., 2019). However, tentacle clubs with structure similar to that of the moribund squid are only found in the former. Assuming they are all the same species, the eye photophores of the first and last, together with the tentacle club of the middle squid are diagnostic of $C$. picteti, the dominant species in this species group in the Indo-West Pacific. The first observation was a mature male with spermatophores visible in Needham's sac. The second was floating moribund or dead; reproduction is terminal in many cephalopods. The third was a mature female with nidamental glands visible through the mantle and with spermatangia implanted on the mantle, fins, and head. It was holding in its arms a long narrow squid with motionless chromatophores. The long, narrow morphology is consistent with the genus Chiroteuthis, although other rare deep-sea squids have similar morphology. As these are the only CAPSTONE observations of any such squids, it seems likely that the unfortunate squid was another Chiroteuthis. This may indicate sexual cannibalism of the male after mating. Conditions expected to be present in sexual cannibalism include (1) terminal reproduction, (2) mature females generally larger than males, and (3) female fecundity increasing with size (Ibánez and Keyl, 2010). Terminal reproduction is typical of deepsea

\section{REFERENCES}

Boletzky, S. V. (1989). Recent studies on spawning, embryonic development, and hatching in the Cephalopoda. Adv. Mar. Biol. 25, 85-115. doi: 10.1016/s00652881(08)60188-1

Burford, B. P., Robison, B. H., and Sherlock, R. E. (2015). Behaviour and mimicry in the juvenile and subadult life stages of the mesopelagic squid Chiroteuthis calyx. J. Mar. Biol. Assoc. 95, 1221-1235. doi: 10.1017/s0025315414001763

Hoving, H.-J., Perez, J. A. A., Bolstad, K. S. R., Braid, H. E., Evans, A. B., Fuchs, D., et al. (2014). The study of deep-sea cephalopods. Adv. Mar. Biol. 67, 235-359.

Ibánez, C. M., and Keyl, F. (2010). Cannibalism in cephalopods. Rev. Fish Biol. Fish. 20, 123-136. doi: 10.1007/s11160-009-9129-y

Roper, C. F. E., and Young, R. E. (2017). Chiroteuthis Picteti Joubin, 1894. Version 10. (Under Construction). Available at: http://tolweb.org/Chiroteuthis_picteti/ 19477/2017.10.10 (accessed June 14, 2019).

Roper, C. F. E., Young, R. E., and Vecchione, M. (2019). Chiroteuthis Orbigny, 1841. Version 26 (Under Construction). Available at: http://tolweb.org/Chiroteuthis/ 19462/2019.03.26 (accessed June 14, 2019).

Shea, E. K., Ziegler, A., Faber, C., and Shank, T. M. (2018). Dumbo octopod hatchling provides insight into early cirrate squids, as is increased fecundity with increased size; I assume these to be the situation for Chiroteuthids. Almost nothing is known about mature Chiroteuthis. Of the only reported mature specimens of $C$. picteti, the female was much larger than the male (Roper and Young, 2017). Therefore C. picteti likely meets the expectations of Ibánez and Keyl (2010) for sexual cannibalism. Furthermore, these three squid, observed close together in time and space, were the only Chiroteuthis observed during the CAPSTONE cruises. This co-occurrence may indicate aggregating by this species for mating.

\section{DATA AVAILABILITY}

The datasets generated for this study are available on request to the corresponding author.

\section{AUTHOR CONTRIBUTIONS}

The author confirms being the sole contributor of this work and has approved it for publication.

\section{ACKNOWLEDGMENTS}

I thank NOAA's Ocean Exploration Program and the CAPSTONE participants, both at sea and ashore.

life cycle. Curr. Biol. 28, R135-R147. doi: 10.1016/j.cub.2018. 01.032

Vecchione, M., Piatkowski, U., and Allcock, A. L. (1998). Biology of the cirrate octopod Grimpoteuthis glacialis (Cephalopoda; Opisthoteuthidae) in the South Shetland Islands, Antarctica. S. Afr. J. Mar. Sci. 20, 421-428. doi: 10.2989/ 025776198784126467

Villanueva, R. (1992). Continuous spawning in the cirrate octopods Opisthoteuthis agassizii and $O$. vossi: features of sexual maturation defining a reproductive strategy in cephalopods. Mar. Biol. 114, 265-275. doi: 10.1007/bf00349529

Conflict of Interest Statement: The author declares that the research was conducted in the absence of any commercial or financial relationships that could be construed as a potential conflict of interest.

Copyright (c) 2019 Vecchione. This is an open-access article distributed under the terms of the Creative Commons Attribution License (CC BY). The use, distribution or reproduction in other forums is permitted, provided the original author(s) and the copyright owner(s) are credited and that the original publication in this journal is cited, in accordance with accepted academic practice. No use, distribution or reproduction is permitted which does not comply with these terms. 